\title{
Emission standards and monitoring strategies in a hierarchical setting
}

\author{
Carmen ARGUEDAS and Sandra ROUSSEAU
}

CITE AS: Arguedas, C. and S. Rousseau (2015). Emission standards and monitoring strategies in a hierarchical setting. Environmental and Resource Economics, vol. 60(3), p. 395-412.

(Doi: 10.1007/s10640-014-9772-1)

\begin{abstract}
In this paper, we consider a hierarchical model of environmental regulation and enforcement to study the standard setting decision made by a national regulator and the monitoring decision made by a local enforcement agency. The problem is interesting due to differences in both available information and objectives at local and national levels. Generally, the national regulator is less informed than the local agency about the characteristics of the polluting agents. This leads to the use of uniform standards and the delegation of the enforcement activity to the local agency. On the one hand, the local agency partially corrects for the inefficiency caused by uniform standards by setting a differentiated inspection strategy. On the other hand, the level of the standard is distorted to partially correct for the inefficiency caused by the divergence between national and local objectives. The interactions between local and national decisions are influenced by the size of the divergence in objectives and the level of environmental damages.
\end{abstract}

Keywords: pollution standards, monitoring, non-compliance.

JEL codes: K42, L51, Q58. 


\section{Introduction}

The organization of environmental monitoring and enforcement is often vertically structured with enforcing authorities at local, regional and national levels. The overview of the structure of environmental inspections in EU member states clearly demonstrates this (IMPEL 2006). For instance, in Denmark the Ministry of Environment establishes the legal framework for environmental policy, while seven regional environmental centers and 98 municipalities carry out environmental inspections and enforcement. Also, in the Netherlands over 500 organizations, including provinces, municipalities and water boards, have roles and responsibilities for environmental monitoring. In Romania, the National Environmental Protection Agency coordinates eight regional environmental protection agencies and 42 local environmental agencies. Etc.

Local authorities are often the first - or even the only - party interacting with businesses, such as small and medium size enterprises. Over time, these local authorities obtain more reliable information on the type of firms and the resources available in their jurisdiction than the national authority. This accurate, locally available information is not passed on in detail to the national level since reporting requirements are limited and often involve aggregate data. For example, Dietz et al. (2003) argue that the Canadian policy to protect cod populations proved a failure due to a lack of specific information at the national level, while this information was available at the local level. They conclude by stressing the need to collect and model both local and aggregated information about resource conditions and to use it in making policy at the appropriate scales. ${ }^{1}$

While enforcement delegation can (partially) solve information problems, however, it seems very likely that policy makers and enforcing authorities pursue different objectives ${ }^{2}$. For example, Mintz (2001) and Kuehn (1996) argue that the interests of state environmental enforcers diverge from those of the federal administration because they are more vulnerable to pressures from elected officials or interest groups, pleas of economic hardship from violators, enforcement budget constraints, and too-close relationships between regulators and regulated entities.

Several scenarios are possible regarding the divergence in objectives. Sometimes, local inspection agencies prioritize deterrence over cost-related considerations, and in some extreme cases they might even act as strict enforcers. Some evidence indeed points to the conclusion that environmental inspection agencies are mainly concerned with deterrence and only on a secondary level with the compliance cost burden placed on the regulated industry (see Firestone 2002, 2003; Heyes and Kapur, 2009). In other instances, green local agencies

\footnotetext{
1 The process of a federal government delegating the legal authority to implement and enforce certain federally designed policies to states is often termed 'partial preemption' (Scheberle 1997; Hedge et al. 1991; Crotty 1987). Partial preemption has been used for major environmental, social welfare, occupational safety and other programs. One of the motivations for partial preemption mentioned by Welborn (1988) is that states can use their more intimate knowledge of the regulated entities and problems to implement more effective and efficient programs. This is exactly the context we are considering in the current paper.

2 The choice of the inspection agency's objective function has already been subject of debate. Cohen (2000), Firestone $(2002,2003)$ and Heyes and Kapur (2009) provide extensive summaries of the different arguments and assumptions made in various studies.
} 
are more concerned about environmental damages in the regulated region than the national agency. Yet another possibility is to consider that inspection agencies place a larger weight on firms' operating costs than the national regulator does. This implies that inspection agencies do not act as strict enforcers, but that they balance environmental considerations with economic concerns such as stimulating the local economy. This approach is consistent with Harford and Harrington (1991) and Stranlund (2007) who assume that part of the costs that the agency takes into account consist of the compliance cost burden on the regulated industry. Some supporting evidence is found by Makkai and Braithwaite (1992) in the case of health officials inspecting nursing homes in Australia, and Muehlenbachs et al. (2013), in the case of inspectors sent to offshore oil and gas platforms in the Gulf of Mexico. Both empirical studies find that influence often takes on more subtle forms of persuasion rather than bribery or corruption and can, for instance, be based on inspectors' past job experience in the private sector.

In this paper, we model a hierarchical structure of environmental regulation to study the standard setting decision made by a national regulator and the monitoring decisions made by the local enforcement agencies. This issue is clearly relevant due to the differences in both information and objectives mentioned above. However, to our knowledge, there are no theoretical studies which examine the interaction between environmental standard setting by federal states and enforcement activities by regional authorities, while capturing the influence of these two distortions. ${ }^{3}$

We consider a scenario where a national regulator minimizes all social costs, including compliance costs for the industry, environmental damages and enforcement costs. A local inspection authority considers all these costs as well, but it places different weights on the various components than those placed by the national regulator. Also, we assume that the national regulator does not have any information about the firms' compliance costs at the micro level, while the local agency does have perfect information in this respect. This leads the national regulator to set a uniform standard within the industry and to delegate the enforcement activity to the local inspection agency.

Our results are twofold. First, we show that the local agency can partially correct for the inefficiency caused by the uniform standard by setting a differentiated inspection strategy. Interestingly, the agency can select the inspection strategy to induce non-compliance with the standard, if the uniform standard set by the regulator is sufficiently strict and the agency is rather concerned about firms' compliance costs. Second, we find that the national regulator sets the standard to correct for the inefficiency caused by the divergence in objectives between national and local authorities. For example, if the local agency is very much concerned about firms' compliance costs, inspections will be less frequent, since the profitability of firms is more highly valued by the local agency than environmental damages. In this context, the national regulator might opt to restrict the standard (even at the expense of some degree of compliance) to limit environmental damages. On the other hand, if the local

\footnotetext{
${ }^{3}$ In the empirical literature, one exception is Atlas (2007), who examines whether states shirk enforcement responsibilities in their principal-agent relationship with the federal government when implementing a delegated environmental program. This study also evaluates determinants of environmental enforcement stringency, particularly whether penalties for violations of US hazardous waste policies are lower when imposed by states than those imposed by the federal government.
} 
agency is mainly concerned about deterrence, inspections will be more frequent, since compliance with the rules is more highly valued by the agency than firms' economic performance. Thus the national regulator might then opt to weaken the standard (even at the expense of some environmental damage) to limit the regulatory burden for the industry.

The remainder of the paper is organized as follows. In section 2, we discuss the relevant related literature. In section 3, we present the model. In section 4, we derive the results and discuss some policy implications. We conclude in section 5. All the proofs are available in the Appendix.

\section{Overview of the relevant literature}

The endogenous determination of standards and monitoring strategies has been previously studied in the literature, but not in a hierarchical setting (see, for example, Arguedas 2008). Saha and Pool (2000) and Decker (2007) consider hierarchical settings where the federal government sets the penalty for non-compliance and the local authority engages in monitoring and enforcement, but these authors do not address the information asymmetry concerning firm characteristics between local and federal administrations analyzed here. Jones and Scotchmer (1990) also take the hierarchical approach, but there the standard is exogenous and the local agency focuses only on deterrence, as opposed to the more general objective function for the local agency considered here. There, the instrument used by the national regulator to influence the agency's distorted decisions is the size of the budget allocated to the agency, while our main points can be made without explicitly restricting the monitoring budget. In our paper, the national regulator uses the level of the emission standard to correct possible distortions, while the size of the budget is treated exogenously. Decker (2007) also considers a hierarchical regulatory structure with exogenous standards. There, the regulator responsible for setting the fines is a social costs minimizer while the agency responsible for enforcement minimizes the sum of enforcement costs and reputation costs related to failures in undertaking proper enforcement efforts.

Informational asymmetries have also been studied in several settings in the literature on fiscal federalism. For instance, Bordignon et al. (2001) investigate the optimal intergovernmental redistribution of federally collected tax income over two regional governments, when information on regional circumstances, such as the size of the tax base or the market value of properties, is not known at the federal level. Also the link between public good provision such as environmental quality and fiscal policies has been studied. For instance, Cremer et al. (1996) and Bucovetsky et al. (1998) consider asymmetric information by assuming that the federal government has no information concerning regional preferences for public goods, whereas Raff and Wilson (1997) and Cornes and Silva (2000) study asymmetric information between federal and regional governments over the local technology for producing local public goods.

As noted by Cohen (1987), the environmental enforcement problem closely resembles a principal-agent problem with moral hazard (see, e.g., Townsend, 1979; Laffont and Martimort, 2001). Moral hazard arises since firms (agents) must take some costly, 
unobservable action to abate emissions, and the contract with the enforcement authority (principal) specifies the inspection probability and the penalty for non-compliance, both jointly determining the expected amount that firms must pay if caught in violation. Since enforcement is costly, the optimal enforcement mechanism may be one in which ex post the enforcement authority does not monitor all the firms, but in which ex ante the firm complies with the environmental regulation on the basis of the expected detection probability (Cohen, 1987).

\section{Model}

We consider the problem depicted in Figure 1. A national regulator sets a pollution standard, denoted by $\bar{e}$, and a unit fine for non-compliance, denoted by $f$ (and treated as exogenous in this paper ${ }^{4}$ ), in a representative region subject to environmental regulation. ${ }^{5}$ In this region, a local authority is responsible for enforcing the pollution standard imposed on a number of polluting firms. The local agency sets the probability of inspecting each firm $i$ in the region, $p_{i}$ (where $\left.0 \leq p_{i} \leq 1\right)$ to verify firms' compliance with the standard. ${ }^{6}$

Each firm selects the emissions level $e_{i}$ and, therefore, whether to comply or not with the standard $\bar{e}$. In case the firm exceeds the standard and it is discovered by the local agency, then the exogenous fine is levied, which is assumed to be linear in the degree of violation: ${ }^{7}$

$$
F=f \max \left\{0 ; e_{i}-\bar{e}\right\}, f>0
$$

\section{[INSERT FIGURE 1 ABOUT HERE]}

\footnotetext{
${ }^{4}$ The fine is exogenous in our model for two reasons. Firstly, in a context as ours with risk neutral firms, a conceptual model in which the emission standard, the fine and the inspection probability are all endogenous typically results in multiple equilibria. The basic reason is that the expected fine as such drives firms' compliance decisions, and therefore, there exists an infinite number of combinations of the inspection probability and the fine which result in the same level of compliance (but see Arguedas 2008 for an exception when the social costs of collecting sanctions are considered). Secondly, selecting the optimal standard (given the fine) provides more flexibility to the regulator than selecting the optimal fine (given the standard), since the fine can only provide abatement incentives for emission levels above the legal standard, while setting the standard can in principle provide abatement incentives for any emission level.

${ }^{5}$ In our setting, the national regulator faces uncertainty with respect to the (marginal) abatement costs. So, according to Weitzman (1974), emission standards are the preferred instrument as long as the slope of the marginal damage curve is steeper than the slope of the marginal abatement cost curve. By restricting the national regulator to select the level of a uniform emission standard, we implicitly assume that the slope of the marginal damage function is indeed steeper than that of the marginal abatement cost curve.

${ }^{6}$ For example, in Sweden local environmental agencies can set their own priorities for compliance monitoring, but the law does not give them discretion in determining sanctions. The Autonomous Communities in Spain also have complete discretion in compliance monitoring, but the monetary sanctions they impose must conform to national provisions that define upper and lower limits for administrative penalties for particular types of offenses (see Mazur, 2011).

${ }^{7}$ In practice, a linear specification of fines is often encountered for civil fines, since this structure is easy to understand by firms, citizens and administrations. Moreover, Arguedas (2008) shows in a theoretical model of pollution standards that linear penalties are socially preferred if the regulator is entitled to choose the structure of the fine.
} 
We now discuss the objective functions and decision variables of the firms, the local agency and the national regulator in more detail.

\subsection{Firms}

Assume there are $N$ polluting firms in the region. The emission level of firm $i$ is denoted as $e_{i} \leq e_{i}^{o}$, where $e_{i}^{o}$ is the emission level without regulation in place. The firm can reduce its emissions below the maximum level $e_{i}^{o}$ at a cost which depends on the pollution level $e_{i}$ and on the parameter $\theta_{i}$, which defines the firms' type. The abatement cost of a firm of type $\theta_{i}$ is represented by the function $c\left(\theta_{i}, e_{i}\right)$, which has the following specification: $c_{e}\left(\theta_{i}, e_{i}\right)<0$ for all $e_{i}<e_{i}^{o}, c_{e}\left(\theta_{i}, e_{i}^{o}\right)=0, c_{e e}\left(\theta_{i}, e_{i}\right)>0$ for all $e_{i} \leq e_{i}^{o}$. Assume also that the third order derivative is negligible.

For simplicity, we assume there are two firm types: high-cost firms $\left(\theta_{H}\right)$ and low-cost firms $\left(\theta_{L}\right)$. The number of high-cost (low-cost) firms is $N_{H}\left(N_{L}\right)$, such that $N_{H}+N_{L}=N$. A high-cost firm has higher total and marginal abatement costs for each level of emissions than a low-cost firm. Thus, $c\left(\theta_{H}, e_{i}\right)>c\left(\theta_{L}, e_{i}\right)$ and $c_{e}\left(\theta_{H}, e_{i}\right)<c_{e}\left(\theta_{L}, e_{i}\right)$. Also, we assume $c_{e e}\left(\theta_{H}, e_{i}\right) \leq c_{e e}\left(\theta_{L}, e_{i}\right)$.

The aggregate level of emissions in the region is $E=\sum_{i=H, L} N_{i} e_{i}$. These emissions cause environmental damages equal to $D(E)$ with $D^{\prime}(E)>0$ and $D^{\prime \prime}(E) \geq 0$.

The objective of each (risk-neutral) firm type is to choose the pollution level that minimizes the sum of abatement costs and expected fines. Therefore, for a given regulatory policy $\left\{\bar{e}, f, p_{i}\right\}$ a firm of type $i$ solves the following problem:

$$
\min _{e_{i}}\left[c\left(\theta_{i}, e_{i}\right)+p_{i} f \max \left\{0 ; e_{i}-\bar{e}\right\}\right] .
$$

\subsection{The local agency}

In the region, the local inspection agency is responsible for enforcing environmental regulation. We assume that the local agency has perfect information on the type of each firm, but monitoring is still needed to formally document a violation. We assume that the cost per inspection is $m>0$ and that monitoring is perfectly accurate. Also, we assume that the local agency can credibly commit to a particular inspection frequency. ${ }^{8}$

\footnotetext{
${ }^{8}$ For example, inspections might require labor and measuring equipment that need to be purchased and deployed. Also, pre-commitment can be justified on reputational grounds, see Garvie and Keeler (1994), Stranlund and Dandha (1999) or, more recently, Macho-Stadler and Perez-Castrillo (2010). However, some other authors have considered monitoring strategies in settings where the agency cannot a priori commit to a specific monitoring frequency (see, for example, Grieson and Singh, 1990 and Franckx, 2002).
} 
The objective of the local inspection agency is to choose inspection probabilities for each firm type, $p_{i}$, taking environmental damages caused by aggregate emissions $(D(E))$, firms' abatement costs $\left(\sum_{i} N_{i} c_{i}\left(\theta_{i}, e_{i}\right)\right)$, and monitoring costs $\left(m \sum_{i} N_{i} p_{i}\right)$ into account. As in Keeler (1995), we introduce the parameter $\psi$ to reflect the importance given by the local inspection agency to abatement costs in the social cost minimization problem. In particular, if $\psi=1$, the agency acts as a social costs minimizer and its objective is aligned with that of the national regulator, as we will see later on. However, the agency's objective diverges from the national regulator's objective when $\psi \neq 1$. For example, if concerns about firms' operating costs dominate, then $\psi>1$. And if concerns about deterrence dominate, then $\psi<1$. We treat the parameter $\psi$ as exogenous, since it typically depends on a wide variety of non-modelled factors such as past interactions with firms, political influence and the general viewpoint of the local enforcement agency.

Therefore, the optimization problem of the inspection agency is the following:

$$
\min _{p_{i}} D(E)+\psi \sum_{i} N_{i} c_{i}\left(\theta_{i}, e_{i}\right)+m \sum_{i} N_{i} p_{i}
$$

considering that firms react strategically to the regulatory policy $\left\{\bar{e}, f, p_{i}\right\}$, as explained above. ${ }^{9}$

\subsection{The national regulator}

To protect environmental quality, the national government selects a uniform emission standard $\bar{e}$ for all the firms in the region. We assume that the national government knows the number of firms of each type $i$, but does not know the exact type of each individual firm due to the aggregated and incomplete information flow between government levels. ${ }^{10}$

We assume that the objective of the national government is to choose the emission standard that minimizes social costs in the region, i.e., environmental damages, firms' abatement costs and monitoring costs associated with the inspection probability $p_{i}$ selected by the local agency. Therefore, the optimization problem of the national regulator is the following:

\footnotetext{
${ }^{9}$ As already pointed out in the introduction, one could alternatively consider a green local agency which is mainly concerned about environmental damages; or a local authority mainly concerned about enforcement costs. These modelling alternatives would imply to place the parameter $\psi>1$ in front of environmental damages or monitoring costs, respectively, in the objective function of the local authority. Fortunately, our results do not qualitatively change under these alternative assumptions, but we will specifically comment on the exact differences later on in footnotes 13 and 17.

${ }^{10}$ The informational advantage of the local inspection agency is exogenous in this model. More realistic would be to assume that the local authority makes probabilistic assessments about the cost structure of the firms based on past performance, instead of directly assuming perfect information. However, including such a learning structure would complicate matters without adding too much insight into the analysis. An illustration of the difficulties found when characterizing the optimal monitoring policy under this learning process in a nonhierarchical setting can be found in Arguedas and Rousseau (2012).
} 


$$
\min _{\bar{e}} D(E)+\sum_{i} N_{i} c_{i}\left(\theta_{i}, e_{i}\right)+m \sum_{i} N_{i} p_{i}
$$

where firms react strategically to the regulatory policy and the local enforcer authority sets the inspection probability, as explained above.

To summarize, after the standard $\bar{e}$ is set by the national regulator and made public knowledge, the agency announces an inspection probability $p_{i}$ for each firm type $i \in\{H, L\}$. Then, each firm reacts to the regulatory policy by selecting the pollution level. In the next section, we solve this problem backwards in order to find the sub-game perfect equilibrium.

\section{Results}

First we look at firms' behavior when they are confronted with a uniform emission standard at the regional level. Next we derive the optimal inspection strategy for the environmental agency conditional on the stringency of the standard. Finally, we investigate the choice of the emission standard made by the national government while taking firms' and local agency's reactions within the region into account.

\subsection{Firms' behavior}

As explained in the previous section, firms choose their emissions levels so as to minimize expected costs, consisting of abatement costs and expected fines for non-compliance, see equation (1). The solution of this optimization problem is presented next.

Lemma 1. Given $\left\{\bar{e}, f, p_{i}\right\}$, firm i's optimal emission level, $\tilde{e}_{i}$, is given by the conditions:

$$
\begin{gathered}
c_{e}\left(\theta_{i}, \tilde{e}_{i}\right)+p_{i} f \geq 0, \\
e_{i}^{o} \geq \tilde{e}_{i} \geq \bar{e}, \\
{\left[c_{e}\left(\theta_{i}, \tilde{e}_{i}\right)+p_{i} f\right]\left[\tilde{e}_{i}-\bar{e}\right]=0 .}
\end{gathered}
$$

The intuition of this result is straightforward. Given the policy $\left\{\bar{e}, f, p_{i}\right\}$, firm $i$ can decide to either comply with the standard, or not. The optimal strategy is to comply when the marginal expected penalty for non-compliance is larger than the marginal abatement cost savings of exceeding the standard; that is, when $p_{i} f \geq-c_{e}\left(\theta_{i}, \bar{e}\right)$. In that case, the optimal strategy is $\tilde{e}_{i}=\bar{e} .{ }^{11}$ However, the optimal strategy is to exceed the standard if the marginal expected penalty is below the marginal abatement cost savings at the standard. In that case, the firm

\footnotetext{
${ }^{11}$ In a static model such as ours, the firm never chooses an emission level strictly below the standard: it just increases abatement costs, but there are no penalty savings.
} 
chooses the emission level such that marginal abatement cost savings and marginal expected fines are equal. Therefore, $\tilde{e}_{i}>\bar{e}$ and $c_{e}\left(\theta_{i}, \tilde{e}_{i}\right)+p_{i} f=0$.

From Lemma 1, we can define the threshold inspection probability for each firm type, such that compliance with the standard is ensured above that threshold, as follows:

$$
\bar{p}_{i}=-\frac{c_{e}\left(\theta_{i}, \bar{e}\right)}{f}
$$

Obviously, $\bar{p}_{H}>\bar{p}_{L}$, since $c_{e}\left(\theta_{H}, e_{i}\right)<c_{e}\left(\theta_{L}, e_{i}\right)$ for all $e_{i}$. Thus, $p_{i} \geq \bar{p}_{i}$ ensures compliance with the standard, i.e., $\tilde{e}_{i}=\bar{e}$. However, $p_{i}<\bar{p}_{i}$ ensures that firms of type $i$ exceed the standard, i.e., $\tilde{e}_{i}>\bar{e}$ and $c_{e}\left(\theta_{i}, \tilde{e}_{i}\right)+p_{i} f=0$. This expression defines an implicit relationship between the inspection probability and the induced emission level, such that:

$$
\frac{\partial e_{i}}{\partial p_{i}}\left(\theta_{i}, e_{i}\right)=-\frac{f}{c_{e e}\left(\theta_{i}, e_{i}\right)}<0,
$$

which represents the effect on emissions of a marginal increase in the inspection probability, such that the larger the probability, the lower the emission level. Our assumptions concerning the abatement cost function ensure that the impact of the inspection frequency on emissions is constant, and that high-cost firms react more than low-cost firms to an increase in the probability of inspection (in terms of emission reduction), independently of the emission level. That is:

$$
-\frac{\partial e_{H}}{\partial p_{H}}\left(\theta_{H}, e_{H}\right)>-\frac{\partial e_{L}}{\partial p_{L}}\left(\theta_{L}, e_{L}\right)
$$

\subsection{Local agency behavior}

The local inspection agency knows the specific type of each firm, and is thus able to differentiate its monitoring strategy depending on the type. However, monitoring is still necessary to formally document a violation so as to allow prosecution and sanctioning. As explained in the previous section, the agency's optimization problem is the following:

$$
\begin{array}{ll}
\min _{p_{H}, p_{L}} & D(E)+\psi \sum_{i=H, L} N_{i} c\left(\theta_{i}, e_{i}\right)+m \sum_{i=H, L} N_{i} p_{i}, \\
\text { s.t. } & c_{e}\left(\theta_{i}, e_{i}\right)+p_{i} f=0 ; e_{i} \geq \bar{e} ; e_{i}^{o} \geq e_{i} ; i=H, L,
\end{array}
$$

where the constraints represent the firm types' best responses, as established in Lemma 1.

The stringency of the emission standard crucially influences the agency's monitoring options. Remember that the local agency has no power to control firm behavior for emission levels below the national standard $(\bar{e})$, but it can induce emission levels above $\bar{e}$ through the 
implicit expression $c_{e}\left(\theta_{i}, e_{i}\right)+p_{i} f=0$ or, equivalently, through the inspection probability $p_{i}=-\frac{c_{e}\left(\theta_{i}, e_{i}\right)}{f}$. Interestingly, this expression is independent of the emission standard due to the linear nature of the fine for non-compliance. Substituting this inspection probability into the objective function of problem (5) helps us in defining the local agency's preferred emission levels. The agency's objective function is U-shaped, and the minimum of this function $\left(e_{i}^{a}\right)$ is characterized by the first order condition $D^{\prime}=-\psi c_{e}\left(\theta_{i}, e_{i}^{a}\right)+m \frac{c_{e e}\left(\theta_{i}, e_{i}^{a}\right)}{f}$, i.e., marginal damages equal the sum of marginal abatement and marginal monitoring costs at that emissions level. ${ }^{12}$ The local agency can induce compliance or non-compliance with the emission standard depending on the location of such standard with respect to the local agency's preferred emissions levels $e_{i}^{a}$, as we show next.

Lemma 2. Given $\psi$, the local agency's optimal inspection strategy $\left(p_{H}^{*}, p_{L}^{*}\right)$ is the following:

(i) $p_{i}^{*}=-\frac{c_{e}\left(\theta_{i}, e_{i}^{a}\right)}{f}$, if $\bar{e}<e_{i}^{a}$.
(ii) $p_{i}^{*}=\bar{p}_{i}=-\frac{c_{e}\left(\theta_{i}, \bar{e}\right)}{f}$, if $\bar{e} \geq e_{i}^{a}$.

Case (i) in Lemma 2 corresponds to the situation where the emission standard is below the local agency's preferred emissions level $e_{i}^{a}$. In this case, the local agency can induce $e_{i}^{a}$ by means of the inspection probability $p_{i}^{*}=-\frac{c_{e}\left(\theta_{i}, e_{i}^{a}\right)}{f}$. This monitoring strategy results in noncompliance, since $e_{i}^{a}>\bar{e}$. However, under case (ii) in Lemma 2, the national standard is (weakly) above the local agency's preferred emissions level, $e_{i}^{a}$. Since the local agency cannot induce emission levels below the standard, the best the agency can do in this case is to induce compliance with the standard by means of the threshold probability $\bar{p}_{i}=-\frac{c_{e}\left(\theta_{i}, \bar{e}\right)}{f}$.

Lemma 2 can be illustrated by means of Figure 2. We consider two firm types in the analysis and our assumptions ensure that $e_{L}^{a}<e_{H}^{a}$. Thus, we can distinguish three cases depending on the location of the emission standard with respect to the local agency's preferred emission

\footnotetext{
${ }^{12}$ If the weight that the local agency attributed to firms' abatement costs $(\psi)$ were sufficiently large, the local agency's objective function could be decreasing in emissions. In this case, the local agency's preferred emissions levels would be the business-as-usual levels $\left(e_{i}^{0}\right)$, since an infinitesimal reduction of emissions from those levels would result in small marginal damage savings as compared to the corresponding additional marginal abatement costs and marginal monitoring costs of that emissions reduction. In that case, the optimal strategy for the local agency would be to leave firms uninspected.
} 
levels $e_{L}^{a}$ and $e_{H}^{a}$ : a stringent standard $\left(\bar{e}<e_{L}^{a}\right)$, a moderate standard $\left(e_{L}^{a} \leq \bar{e}<e_{H}^{a}\right)$ and a lax standard $\left(\bar{e} \geq e_{H}^{a}\right)$. The upper graph shows the relationship between the stringency of the standard and the optimal inspection probability. The lower graph shows the resulting firm types' best responses to both the standard and the inspection probability.

\section{[INSERT FIGURE 2 ABOUT HERE]}

Assume first that the standard is set at a sufficiently stringent level $\left(\bar{e}<e_{L}^{a}\right)$. In this case, the agency can implement its most preferred outcome $\left(e_{H}^{a}, e_{L}^{a}\right)$ by setting the inspection probabilities defined in part (i) of Lemma 2. Our assumptions ensure that the probability associated with the high-cost firms is larger than the probability associated with the low-cost firms. In that range, the required probabilities do not depend on the level of the standard, since the fine is linear in the degree of non-compliance and, therefore, the marginal fine is not affected by the size of the violation. In that range, both types of firms exceed the national standard $\bar{e}$, but the size of the violation is smaller for low-cost firms than for high-cost firms, since $e_{L}^{a}<e_{H}^{a}$. The latter is illustrated in the lower graph of Figure 2, where for the national standard below $e_{L}^{a}$, both types' induced emissions levels are above the $45^{\circ}$ degree line.

Secondly, if the standard is set at a moderate level $\left(e_{L}^{a} \leq \bar{e}<e_{H}^{a}\right)$, the agency cannot implement its most preferred outcome $\left(e_{H}^{a}, e_{L}^{a}\right)$ since low-cost firms never select a pollution level below the standard (see Lemma 1). As a consequence, the best the agency can do in this case is to induce low-cost firms to fully comply with the standard (otherwise, the induced pollution level would be further away from the agency's most preferred level) and to induce high-cost firms to select the pollution level $e_{H}^{a}$ above the standard. Thus the inspection authority selects a different type of strategy for each firm type: $p_{H}^{*}=-\frac{c_{e}\left(\theta_{H}, e_{H}^{a}\right)}{f}$ and $p_{L}^{*}=\bar{p}_{L}$, where $\bar{p}_{L}$ is the threshold probability given by (2). In this region, the inspection probability selected for the high-cost type is independent of the standard since the marginal fine is constant and, therefore, unaffected by the level of the standard. However, the threshold probability attached to the low-cost type is decreasing in the standard, since the less stringent the standard, the less monitoring resources are needed to induce the low-cost firms to comply with the standard (see expression (2) and recall that $\left.c_{e e}\left(\theta_{i}, e_{i}\right)>0\right)$.

Finally, if the standard is lax $\left(\bar{e} \geq e_{H}^{a}\right)$, the local agency cannot implement its most preferred outcome $\left(e_{H}^{a}, e_{L}^{a}\right)$ either, and the best the agency can do in this case is to induce both firm types to comply with the standard. Then, the optimal inspection strategy involves setting the threshold probabilities to induce full compliance $\left(p_{H}^{*}=\bar{p}_{H}\right.$ and $\left.p_{L}^{*}=\bar{p}_{L}\right)$. High-cost firms are inspected more frequently than low-cost firms and both firm types fully comply with the standard $\bar{e}$. In this region, both threshold inspection probabilities are decreasing in the level of the standard, until the level of the standard eventually reaches the business-as-usual 
outcome (for illustration purposes, this level coincides for both firm types in Figure 2, but this need not necessarily be the case).

As can be seen in Figure 2, the local inspection agency uses its informational advantage and treats both firm types differently. Therefore, it lowers the inefficiency of using a uniform emission standard to regulate heterogeneous firms in the region. However, the weight that the local agency attributes to firms' abatement costs $(\psi)$ creates a distortion in the solution, since this weight crucially affects the local agency's preferred emissions levels, $e_{i}^{a}$. Clearly, the larger the weight attributed to firms' abatement costs, the larger the preferred emissions levels and therefore, the more likely the inspection strategy will result in firms' non-compliance (in other words, the larger the stringent and moderate standard regions in Figure 2). The national government considers this distortion when it sets the emission standard, as we explain next. ${ }^{13}$

\subsection{Standard setting by the national regulator}

We now study the standard setting decision at the national level. As mentioned before, the regulator aims to minimize all social costs associated with the environmental policy at the regional level by selecting the appropriate emission standard while taking into account firms' and the local agency's reactions to the standard.

Therefore, the problem the regulator at the national level solves is the following:

$$
\begin{array}{cc}
\min _{\bar{e}} & D(E)+\sum_{i=H, L} N_{i} c\left(\theta_{i}, e_{i}\right)+m \sum_{i=H, L} N_{i} p_{i}, \\
\text { s.t. } & p_{i}=\left\{\begin{array}{ll}
-\frac{c_{e}\left(\theta_{i}, e_{i}^{a}\right)}{f}, & \bar{e}<e_{i}^{a} \\
-\frac{c_{e}\left(\theta_{i}, \bar{e}\right)}{f}, & \bar{e} \geq e_{i}^{a}
\end{array}\right\},
\end{array}
$$

where $\left(e_{i}^{a}\right)$ is the local agency's preferred emissions levels, implicitly defined by $D^{\prime}=-\psi c_{e}\left(\theta_{i}, e_{i}^{a}\right)+m \frac{c_{e e}\left(\theta_{i}, e_{i}^{a}\right)}{f}$, as explained in the previous subsection.

Firms react to the standard in the way illustrated in Figure 2. If the standard is set below the emission level preferred by the inspection agency, $\bar{e} \leq e_{i}^{a}$, the agency designs the inspection policy such that the firm ends up polluting $e_{i}^{a}$. However, if the standard is set above the emission level preferred by the inspection agency, $\bar{e}>e_{i}^{a}$, then the agency chooses the monitoring probability such that the firm ends up complying with the standard $\bar{e}$.

\footnotetext{
13 If we alternatively assumed a larger weight on monitoring costs or environmental damages in the local authority's objective function, the exact placement of both $e_{L}^{a}$ and $e_{H}^{a}$ would surely change, but we would still keep the three regions identified in Figure 2, since $e_{L}^{a}<e_{H}^{a}$. The larger the weight attributed to enforcement costs, the larger both $e_{L}^{a}$ and $e_{H}^{a}$ and, therefore, the more to the right the stringent and moderate standard regions in Figure 2. Alternatively, the larger the weight attributed to environmental damages, the lower both $e_{L}^{a}$ and $e_{H}^{a}$ and, therefore, the more to the left the corresponding stringent and moderate standard regions.
} 
Consequently, any standard below $e_{L}^{a}$ results in the same pollution levels $\left(e_{L}^{a}, e_{H}^{a}\right)$ with the same monitoring resources, since in this case the inspection agency selects the inspection probability $p_{i}=-\frac{c_{e}\left(\theta_{i}, e_{i}^{a}\right)}{f}, i=H, L$, which is independent of $\bar{e}$. For this reason the national regulator never selects the emission standard in the stringent regulatory region where $\bar{e}<e_{L}^{a}$.

Therefore, we can restrict our analysis to $\bar{e} \geq e_{L}^{a}$. As a result, low-cost firms always comply with the standard, while high-cost firms may or may not comply. Thus we still have two cases to examine: the moderate regulatory region $\left(\bar{e}<e_{H}^{a}\right)$ and the lax regulatory region $\left(\bar{e} \geq e_{H}^{a}\right)$.

Intuitively, if marginal monitoring costs relative to marginal damages and marginal abatement costs are high, then the national regulator sets a lax standard $\bar{e} \geq e_{H}^{a}$ and both types of firms comply with the standard. However, if marginal monitoring costs relative to marginal damages and marginal abatement costs are low, then the national regulator sets a moderate standard $e_{L}^{a} \leq \bar{e} \leq e_{H}^{a}$ and only low-cost firms comply. Hence, the relationship between monitoring costs and induced pollution is the expected one: higher monitoring costs result in larger pollution levels and vice versa. However, the results regarding compliance levels seem counterintuitive: higher monitoring costs result in higher compliance rates, and vice versa. This result comes from the fact that the local inspection agency only induces firms to comply as long as the national regulator announces a standard above the agency's preferred emission level $e_{i}^{a}$.

Now, it is useful to define the level of the uniform emission standard that minimizes the national regulator's objective function defined in (6), (naively) assuming that both firm types comply with the standard. We denote this level as $e^{u}$ and it is characterized by the first order condition:

$$
\sum_{i=H, L} N_{i}\left\{D^{\prime}+c_{e}\left(\theta_{i}, e^{u}\right)-m c_{e e}\left(\theta_{i}, e^{u}\right) / f\right\}=0
$$

Obviously, this emission level can only be implemented as long as the local agency's preferred emission level for the high-cost type $e_{H}^{a}$ is below $e^{u}$. Otherwise, the best the national regulator can do is to let the high-cost firms pollute $e_{H}^{a}$ and induce the low-cost firms to comply with a restricted emission standard. This restricted emission standard $e^{r}$ is set such that:

$$
D^{\prime}+c_{e}\left(\theta_{L}, e^{r}\right)-m c_{e e}\left(\theta_{L}, e^{r}\right) / f=0
$$

Simply comparing (7) and (8), note that $e^{r}<e^{u}$.

The solution of the national regulator's problem is then summarized next.

Proposition 1. The optimal emission standard $\bar{e}^{*}$ set by the national regulator is: 
i) $\bar{e}^{*}=e^{u}, \quad$ if $e^{u}>e_{H}^{a}$.

ii) $\bar{e}^{*}=e^{r}, \quad$ if $e^{u} \leq e_{H}^{a}$.

Therefore, the optimal emission standard can induce either full compliance of all firms in the region (case i) or compliance of the low-cost firms only (case ii). The choice crucially depends on the location of $e^{u}$ with respect to $e_{H}^{a}$, where $e^{u}$ is the uniform pollution level that minimizes the sum of environmental damages, abatement costs and monitoring costs in the region, as we have previously characterized in expression (7). Which of the two compliance scenarios emerges crucially depends on the value of $\psi$, that is, the weight that the local agency attributes to abatement costs. This is so because $\psi$ and $e_{H}^{a}$ are positively related: the larger $\psi$, the larger $e_{H}^{a}$, and vice versa.

On the one hand, we can have full compliance of all firms in the region (case i in Proposition 1) if $\psi$ is small enough, i.e., if the local agency does not care much about firms' operating costs. The explanation of the result is simple: since the local agency's preferred pollution levels in this case are small and the associated inspection costs to induce compliance with those levels are large, the national regulator is tempted to pass a regulation that saves on total monitoring costs by relaxing the standard, although at the expense of additional external damages. The level of the standard in this case is the one that minimizes the sum of environmental damages, firms' abatement costs and monitoring costs (i.e., the level $e^{u}$ previously characterized in expression (7)), and both firms' types are induced to comply with the standard. ${ }^{14}$

On the other hand, we obtain partial compliance, with only low-cost firms complying with the standard (case ii in Proposition 1), as long as $\psi>1$, i.e., when the local agency cares about firms' operating costs more than the national regulator does. Full compliance is not possible in this scenario..$^{15}$ The local inspection agency less frequently inspects the firms in the region since now the profitability (and survival) of local firms is more highly valued than the deterioration of the environment. Since total monitoring costs are less of a burden in this alternative setting, the national regulator might opt to restrict the standard (and therefore, the induced pollution levels) to limit environmental damages in the region. The level of the standard in this case minimizes the sum of environmental damages and low-cost firms' abatement and monitoring costs (i.e., it corresponds to the restricted level $e^{r}$ previously

\footnotetext{
${ }^{14}$ It is interesting to compare this uniform induced emission level $e^{u}$ with the emissions levels that minimize the national regulator's objective function, i.e., the sum of environmental damages, firms' abatement costs and monitoring costs. We denote these levels by $e_{L}^{*}$ and $e_{H}^{*}$, which are characterized by the first order conditions $D^{\prime}+c_{e}\left(\theta_{i}, e_{i}^{*}\right)-\frac{m c_{e e}\left(\theta_{i}, e_{i}^{*}\right)}{f}=0$. Our assumptions ensure $e_{L}^{*}<e_{H}^{*}$. These ideal pollution levels could be implemented only in the case where the national regulator had all the information about each specific firm and did not need to delegate enforcement to a better informed authority. Note that $e^{u}$ is located between these two ideal pollution levels, that is, $e_{L}^{*}<e^{u}<e_{H}^{*}$. Thus, in this case, high (low) abatement cost firms are induced to pollute less (more) than the corresponding ideal emission levels.

${ }^{15}$ If $\psi>1$, the ideal pollution levels defined in footnote 15 are lower than the local agency's preferred levels, i.e., $e_{i}^{*}<e_{i}^{a}$. In particular, $e_{H}^{*}<e_{H}^{a}$, which implies $e^{u}<e_{H}^{a}$, that is, case (ii) in Proposition 1 .
} 
characterized in expression (8)). As a result, low-cost firms comply with the standard $e^{r}$, and high-cost firms violate the standard and pollute the level $e_{H}^{a}>e^{r} .{ }^{16}$

Summarizing, the national regulator uses the emission standard to (partially) correct for the biased objectives pursued by the local agency. If the local agency does not care much about firms' operating costs, then the standard will be laxer and compliance with that standard will be more likely. If, on the other hand, the local agency puts too much emphasis on firms' operating costs, the standard will be stricter and compliance will be less likely. ${ }^{17}$

\section{Conclusion}

In this paper, we have analyzed the interactions between the environmental standard setting decision by a national regulator and the monitoring decision by a local enforcement agency, assuming that authorities at the local and national levels have different available information and might pursue different objectives.

We have considered an extreme scenario where the local agency perfectly knows firms' compliance costs, while the national regulator has imperfect information in this respect. This leads the national regulator to set a uniform standard within the industry and to delegate the enforcement activity to the local inspection agency. We have found that the local agency can partially correct for the inefficiency caused by the uniform standard by setting a differentiated inspection strategy. This strategy can induce partial (or even full) non-compliance with the standard, if the uniform standard set by the regulator is sufficiently strict and the agency is mainly concerned about firms' abatement costs. Conversely, when the agency mainly focuses on deterrence, the uniform standard set by the regulator will be complied more frequently than socially desired. Also, we have found that the national regulator can set the standard to correct for the inefficiency caused by the divergence in objectives between national and local authorities. The national regulator might impose a less stringent standard to save on monitoring costs when the local agency and the national regulator's objectives do not diverge much. However, the national regulator might opt to restrict the standard if the local agency is more concerned about firms' regulatory costs or to weaken the standard if the local agency is mainly concerned about firms' compliance or about environmental quality.

Thus, by looking at both the environmental policy instrument and the associated monitoring strategy, we have found that the efficiency disadvantage of uniform emission standards is substantially alleviated by the agency's inspection policy. Hence the disadvantage of uniform regulatory standards may be overstated in the literature. Important conditions for this

\footnotetext{
${ }^{16}$ Therefore, in this case, low abatement cost firms are induced to pollute an emission level $e^{r}$ which might be very close to the corresponding ideal level $e_{L}^{*}$ (in fact, these two levels coincide under constant marginal environmental damages), while high abatement cost firms are induced to pollute above the corresponding ideal pollution level, defined in footnote 14 .

${ }^{17}$ The same sort of conclusion can be found if we alternatively assumed that the local agency placed a larger weight than the national authority on monitoring costs or a lower weight than the national authority on environmental damages. In both cases, the national regulator would set a stricter standard and compliance would be less likely.
} 
improvement in the efficiency of the environmental policy are the availability of sufficient resources for the inspection agency and the incorporation of abatement cost considerations in the agency's objective function. Therefore, it might be desirable to influence the form of the agency's objective function by increasing the weight attached to firms' compliance costs. This could be done, for example, by changing the agency's mission statement combined with independent, external evaluation of the agency's performance.

In this paper, we have implicitly considered that collected fines (if any) are redistributed lump-sum in the society. This explains why the specific fine structure is not present in the national regulator's objective function. In fact, fines do not appear in the local agency's objective function either, but we could have considered an alternative scenario in which the local agency placed a different weight on the total expected costs faced by the firms than the national regulator. These expected costs would not only include abatement costs but also possible fines for non-compliance. In the event that the local agency cared more than the national regulator about firms' total expected costs, then the local agency could implicitly "relax" the national standard in cases where such standard induced non-compliance by a particular firm type, and set it equal to the corresponding local agency's preferred emission level. Since the fine is linear in the degree of non-compliance, this implicit increase in the standard would not imply any change in the optimal inspection probability, and the resulting induced emission level would not change either (note that the induced emission level of a particular firm type is equal to the local agency's desired level even when the national standard is set below such locally desired emission level, see Figure 2). From the point of view of the national regulator, this manipulation of the standard by the local regulator would not have any consequences on the level of social costs ${ }^{18}$. In fact, the national regulator does not care about whether fines are actually imposed or not, as long as the induced emission levels and inspection costs do not change. However, this relaxed standard could obviously benefit firms significantly, since firms would be complying with the local standard and would not be punished. To hide the implicit relaxation of the standard, the local agency could also use warnings and compliance orders as an alternative sanction instead of fines. This implies that firms receive an official communication that they were found to be in violation and they are ordered to rectify the situation. Warnings and compliance orders are frequently used in practice (see, e.g., Rousseau, 2009) as a soft sanctioning instrument: detected violators are officially sanctioned, but they face no direct monetary consequences.

The possibility of locally relaxing the standards or setting warnings instead of fining violators is connected with the idea of collusion between the supervisor and the agents. This idea has been explored in the literature on monitoring delegation, (see, for example, Tirole, 1986 and Strausz, 1997) and in the literature on regulatory capture (see, for example, Makkai and Braithwaite, 1992 and Dal Bo, 2006). In our setting, the national regulator delegates the responsibility of monitoring to the local agency, and the local agency would be able to manipulate the outcome of the inspection if doing so is in its best interest. This effectively means that the local agency and the firms would be colluding against the national regulator.

\footnotetext{
${ }^{18}$ In our model we do not attribute social benefits to punishing the guilty or social costs to acquitting the guilty (see e.g. Kitai, 2003), since such fairness considerations are not specifically included in the regulator's objective function.
} 
In order to empirically validate the theory we have developed, it might be interesting to distinguish different groups of countries depending on the degree of delegation of powers from the national regulator to local authorities. Mazur (2011) provides an example of such a classification depending on the degree of decentralization in countries. Then differences in environmental policy regarding instrument choice, stringency, monitoring strategies and sanctions might be identified between the groups. Unfortunately, finding empirical indicators for environmental policy stringency, monitoring strength and compliance levels is notoriously difficult (see, for instance, EAP task force 2006; IMPEL 2008). Thus, it might be equally difficult to proof a causal link between a country's delegation structure and the design of the environmental monitoring and enforcement strategy. 


\section{Appendix}

\section{Proof of Lemma 1}

The first order conditions of this optimization problem are: ${ }^{19}$

$$
\begin{aligned}
& c_{e}\left(\theta_{i}, e_{i}\right)+p_{i} f-\lambda=0, \\
& \lambda \geq 0, e_{i}-\bar{e} \geq 0, \lambda\left[e_{i}-\bar{e}\right]=0,
\end{aligned}
$$

where $\lambda \geq 0$ is the Kuhn-Tucker multiplier. Easily combining these conditions, we obtain the desired result.

\section{Proof of Lemma 2}

Since $c_{e}\left(\theta_{i}, e_{i}\right)+p_{i} f=0$, the Lagrangian of problem (5) can be written as follows:

$$
L=D(E)+\psi \sum_{i=H, L} N_{i} c\left(\theta_{i}, e_{i}\right)-m \sum_{i=H, L} N_{i} \frac{c_{e}\left(\theta_{i}, e_{i}\right)}{f}-\sum_{i=H, L} \alpha_{i}\left[e_{i}-\bar{e}\right]-\sum_{i=H, L} \beta_{i}\left[e_{i}^{o}-e_{i}\right],
$$

where $\alpha_{i} \geq 0, \beta_{i} \geq 0$ are the corresponding Kuhn-Tucker multipliers. Thus, everything can be reduced to obtain the optimal agency's induced emissions levels. ${ }^{20}$ The optimality condition for each firm type is then the following:

$$
N_{i} D^{\prime}+\psi N_{i} c_{e}\left(\theta_{i}, e_{i}\right)-m \frac{c_{e e}\left(\theta_{i}, e_{i}\right)}{f}-\alpha_{i}+\beta_{i}=0, i=H, L .
$$

We concentrate on the case where $\beta_{i}=0 .{ }^{21}$ On the one hand, the optimality condition for the interior solution, where $\alpha_{i}=0$ and $e_{i} \geq \bar{e}$ is the following:

$$
D^{\prime}+\psi c_{e}\left(\theta_{i}, e_{i}\right)-m \frac{c_{e e}\left(\theta_{i}, e_{i}\right)}{f}=0 .
$$

Note that this condition is exactly the one that characterizes the agency's preferred emissions levels, $e_{i}^{a}$. Then, $e_{i}=e_{i}^{a} \geq \bar{e}$. These levels can be induced using the implicit expression $c_{e}\left(\theta_{i}, e_{i}\right)+p_{i} f=0$ and, therefore, $p_{i}^{*}=-\frac{c_{e}\left(\theta_{i}, e_{i}^{a}\right)}{f}$.

\footnotetext{
${ }^{19}$ Given the assumptions of our model, these are necessary and sufficient conditions for an optimum. The same applies for the other optimization problem in the paper.

${ }_{20}$ These emissions levels can be induced by the corresponding inspection probabilities using the implicit expression $c_{e}\left(\theta_{i}, e_{i}\right)+p_{i} f=0$.

${ }^{21}$ The case $\beta_{i} \geq 0$ would imply $e_{i}=e_{i}^{0}$ and $\alpha_{i}=0$, which could be induced by $p_{i}=0$.
} 
On the other hand, the corner solution where $\alpha_{i} \geq 0$ and $e_{i}=\bar{e}$ is obtained when $D^{\prime}+\psi c_{e}\left(\theta_{i}, \bar{e}\right)-m \frac{c_{e e}\left(\theta_{i}, \bar{e}\right)}{f} \geq 0$. Comparing this above expression with the one that characterizes $e_{i}^{a}, D^{\prime}+\psi c_{e}\left(\theta_{i}, e_{i}^{a}\right)-m \frac{c_{e e}\left(\theta_{i}, e_{i}^{a}\right)}{f}=0$, and using the assumption of convexity of the objective function, we then have $e_{i}=\bar{e} \geq e_{i}^{a}$. The emissions level in this case, $e_{i}=\bar{e}$, can be induced by the threshold inspection probabilities defined in (2).

\section{Proof of Proposition 1}

Consider first the case where $e^{u} \geq e_{H}^{a}$. The optimization problem is the following:

$$
\begin{array}{ll}
\min _{\bar{e}} & D(E)+\sum_{i=H, L} N_{i} c\left(\theta_{i}, e_{i}\right)+m \sum_{i=H, L} N_{i} p_{i}, \\
\text { s.t. } & p_{i}=-\frac{c_{e}\left(\theta_{i}, \bar{e}\right)}{f}
\end{array}
$$

The first order condition of this problem is:

$$
\sum_{i} N_{i}\left\{D^{\prime}+c_{e}\left(\theta_{i}, \bar{e}\right)-m \frac{c_{e e}\left(\theta_{i}, \bar{e}\right)}{f}\right\}=0,
$$

If we alternatively consider the restricted problem where $e_{L}^{a} \leq e^{u}<e_{H}^{a}$, the optimization problem is now the following:

$$
\begin{array}{ll}
\min _{\bar{e}} & D(E)+\sum_{i=H, L} N_{i} c\left(\theta_{i}, e_{i}\right)+m \sum_{i=H, L} N_{i} p_{i}, \\
\text { s.t. } & p_{H}=-\frac{c_{e}\left(\theta_{i}, e_{H}^{a}\right)}{f} ; p_{L}=-\frac{c_{e}\left(\theta_{i}, \bar{e}\right)}{f}
\end{array}
$$

Now, the first order condition of this problem is simply:

$$
D^{\prime}+c_{e}\left(\theta_{L}, \bar{e}\right)-m \frac{c_{e e}\left(\theta_{L}, \bar{e}\right)}{f}=0 .
$$




\section{References}

Arguedas, C. (2008). To comply or not to comply? Pollution standard setting under costly monitoring and sanctioning. Environmental and Resource Economics, 41(2), 155-168.

Arguedas, C. and S. Rousseau (2012). Learning about compliance under asymmetric information. Resource and Energy Economics, 34(1), 55-73.

Atlas, M. (2007). Enforcement principles and environmental agencies: Principal-agent relationships in a delegated environmental program. Law \& Society Review, 41(4), 939-980

Bordignon, M., Manasse, P. and G. Tabellini (2001). Optimal regional redistribution under asymmetric information. American Economic Review, 91(3), 709-723

Bucovetsky, S., Marchand, M. and P. Pestieu (1998). Tax Competition and Revelation of Preferences for Public Expenditures. Journal of Urban Economics, 44(3), 367-390

Cohen, M.A. (1987). The optimal enforcement strategy to prevent oil spills: An application of a principal-agent model with moral hazard. Journal of Law and Economics, 30(1), 23-51

Cohen, M.A. (2000). Monitoring and enforcement of environmental policy. In: Tietenberg, T. and Folmer, H., International yearbook of environmental and resource economics, vol. III. Edward Elgar Publishers.

Cornes, R.C. and E.C.D. Silva (2000). Local public goods, risk sharing and private information in federal systems. Journal of Urban Economics, 47(1), 39-60.

Cremer, H., Marchand, M. and P. Pestieu (1996). International redistribution through tax surcharge. International Tax and Public Finance, 3(2), 157-173.

Crotty - McGee, P. (1987). The new federalism game: Primacy implementation of environmental policy. Publius, 17, 53-67.

Dal Bo, E. (2006). Regulatory capture: A review. Oxford Review of Economic Policy, 22(2), 203-225

Decker, C.S. (2007). Flexible enforcement and fine adjustement. Regulation \& Governance, 1, 312-328.

Dietz, T., Ostrom, E. and P. Stern (2003). The struggle to govern the commons. Science, 302, 1907-1912

EAP task force (2006). Recommendations on performance measurement for environmental enforcement authorities of Eastern Europe, Caucasus, and Central Asia. Presented at the eight annual meeting of the EECCA Regulatory Environmental Programme Implementation Network, 12-13 June 2006, Tbilisi (Georgia). 
Firestone, J. (2002). Agency governance and enforcement: The influence of mission on environmental decision making. Journal of Policy Analysis and Management, 21(3), 409-426.

Firestone, J. (2003). Enforcement of pollution laws and regulations: An analysis of forum choice. Harvard Environmental Law Review, 27, 105-176.

Franckx, L. (2002). The use of ambient inspections in environmental monitoring and enforcement when the inspection agency cannot commit itself to announced inspection probabilities. Journal of Environmental Economics and Management, 43, 71-92.

Garvie, D. and A. Keeler (1994). Incomplete enforcement with endogenous regulatory choice. Journal of Public Economics, 55, 141-162.

Grieson, R.E. and N. Singh (1990). Regulating externalities through testing. Journal of Public Economics, 41, 369-387

Harford, J.D. and Harrington, W. (1991). A reconsideration of enforcement leverage when penalties are restricted. Journal of Public Economics, 45, 391-395.

Hedge, D.M., Scicchitano, M.J. and P. Metz (1991). The principal-agent model and regulatory federalism. Western Political Quarterly, 44, 1055-1080.

Heyes, A. and S. Kapur (2009). Enforcement missions: Targets vs. budgets. Journal of Environmental Economics and Management, 58(2), 129-140.

IMPEL (2006). Short overview of the organisation of inspections in IMPEL Member States, Norway, acceding and candidate countries 2006. www.impel.eu

IMPEL (2008). Brainstorming on an IMPEL project to develop performance indicators. Final report $n^{\circ} 2008 / 03$. www.impel.eu

Jones, C.A. and S. Scotchmer (1990). The social cost of uniform regulatory standards in a hierarchical government. Journal of Environmental Economics and Management, 19, 61-72.

Kitai, R. (2003). Protecting the guilty. Buffalo Criminal Law Review, 6, 1163-1187.

Kuehn, R.R. (1996). The limits of devolving enforcement of federal environmental laws. Tulane Law Review, 70, 2373-95.

Laffont, J.J. and D. Martimort (2001). The theory of incentives: The principal-agent model. Princeton University Press. 440 pp.

Macho-Stadler, I. and D. Pérez-Castrillo (2010). Optimal monitoring to implement clean technologies when pollution is random. SERIEs, Spanish Economic Association, 1(3), 277304.

Makkai, T. and J. Braithwaite (1992). In and out the revolving door: Making sense of regulatory capture. Journal of Public Policy, 12, 61-78 
Mazur, E. (2011). Environmental enforcement in decentralised governance systems: Toward a nationwide level playing field. OECD environmental working papers, $\mathrm{n}^{\circ} 34$. OECD publishing. http://dx.doi.org/10.1787/5kgb1m60qtq6-en

Mintz, J.A. (2001). Scrutinizing environmental enforcement: A comment on a recent Discussion at the AALS. Journal of Land Use \& Environmental Law, 17, 127-148.

Muehlenbachs, L., Staubli, S. and M. Cohen (2013). The effect of inspector group size and familiarity on enforcement and deterrence. IZA Discussion Paper Series no. 7876

Raff, H. and J.D. Wilson (1997). Income Redistribution with Well-Informed Local Governments. International Tax and Public Finance, 4(4), 407-427.

Rousseau, S. (2009). The use of warnings in the presence of errors. International Review of Law and Economics, 29, 191-201

Scheberle, D. (1997). Federalism and environmental policy: Trust and the politics of implementation. Washington, DC: Georgetown University Press.

Stranlund, J.K. (2007). The regulatory choice of non-compliance in emission trading programs. Environmental and Resource Economics, 38, 99-117.

Stranlund, J.K. and K.K. Dhanda (1999). Endogenous monitoring and enforcement of a transferable emissions permit system. Journal of Environmental Economics and Management, $38,267-282$.

Strautz, R. (1997). Delegation of monitoring in a principal-agent relationship. Review of Economic Studies, 64, 337-357.

Tirole, J. (1986). Hierarchies and bureaucracies: On the role of collusion in organizations. Journal of Law, Economics \& Organization, 2, 181-214.

Townsend, R.M. (1979). Optimal contracts and competitive markets with costly state verification. Journal of Economic Theory, 21, 265-293

Weitzman, M. (1974). Prices versus quantities. The Review of Economic Studies, 41(4), 477491.

Welborn, D.M. (1988). Conjoint federalism and environmental regulation in the United States. Publius, 18, 27-43. 
Figure 1: The regulatory problem

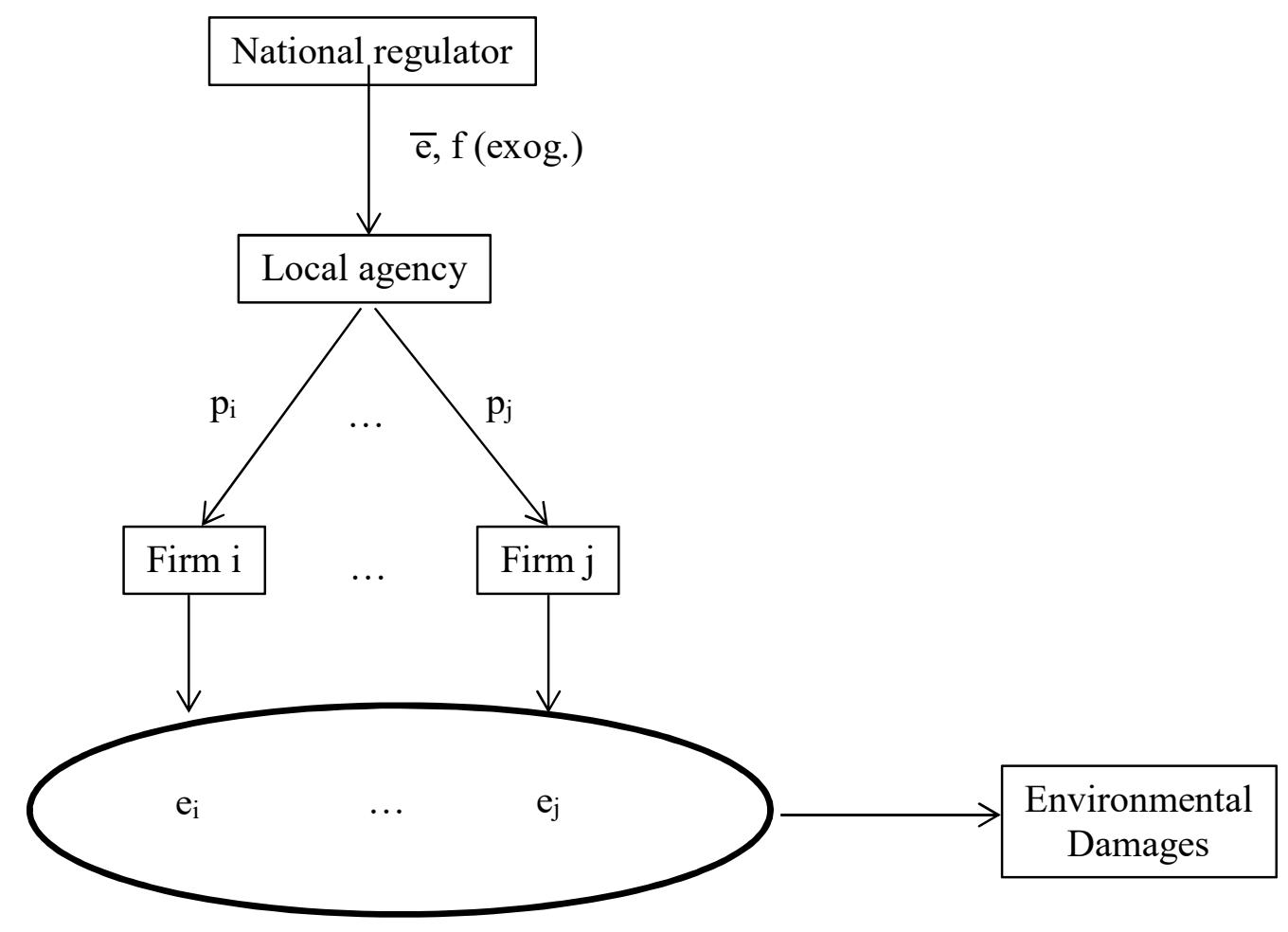


Figure 2: Optimal inspection probabilities

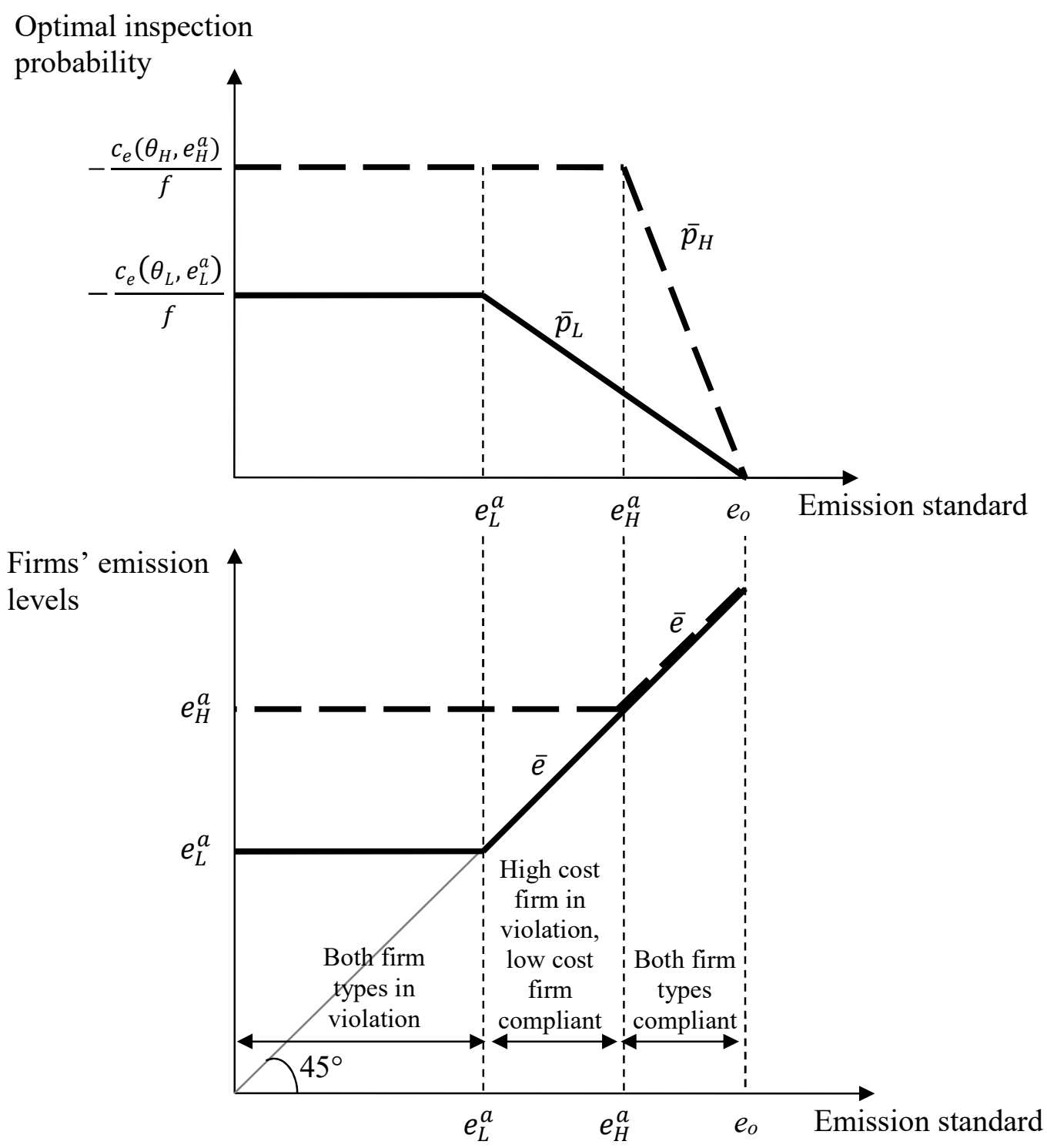

